\title{
Neuroprotective effects of orientin on hydrogen peroxide-induced apoptosis in SH-SY5Y cells
}

\author{
BENJAMIN NGEE TIING LAW ${ }^{1}$, ANNA PICK KIONG LING ${ }^{2}$, RHUN YIAN KOH ${ }^{2}$, \\ SOI MOI CHYE ${ }^{2}$ and YING PEI WONG ${ }^{2}$ \\ ${ }^{1}$ School of Medical Sciences; ${ }^{2}$ Department of Human Biology, Faculty of Medicine and Health, \\ International Medical University, Kuala Lumpur 57000, Malaysia
}

Received May 3, 2013; Accepted November 18, 2013

DOI: $10.3892 / \mathrm{mmr} .2013 .1878$

\begin{abstract}
Neurodegenerative diseases remain a global issue which affects the ageing population. Efforts towards determining their aetiologies to understand their pathogenic mechanisms are underway in order to identify a pathway through which therapeutic measures can be applied. One such pathogenic mechanism, oxidative stress (OS), is widely considered to be involved in neurodegenerative disease. Antioxidants, most notably flavonoids, have promising potential for therapeutic use as shown in in vitro and in vivo studies. In view of the importance of flavonoids for combating OS, this study investigated the neuroprotective effects of orientin, which has been reported to be capable of crossing the blood-brain barrier. The maximum non-toxic dose (MNTD) of orientin against SH-SY5Y neuroblastoma cells was determined using a 3-(4,5-dimethylthiazol-2-yl)-2,5-diphenyltetrazolium bromide (MTT) assay. The effects of the MNTD and the half MNTD ( $1 / 2$ MNTD) of orientin on cell cycle progression and intracellular reactive oxygen species (ROS) levels, as well as the activity of caspases $3 / 7,8$ and 9 after exposure to $150 \mu \mathrm{M}$ of hydrogen peroxide $\left(\mathrm{H}_{2} \mathrm{O}_{2}\right)$ were also determined using flow cytometry, a 2',7'-dichlorodihydrofluorescein-diacetate (DCFH-DA) assay and caspase assay kits, respectively. The results revealed that orientin at $\leq 20 \mu \mathrm{M}$ was not cytotoxic to SH-SY5Y cells. After treatment with orientin at the MNTD, the percentage of apoptotic cells was significantly reduced compared with that in cells treated with $150 \mu \mathrm{M} \mathrm{H}_{2} \mathrm{O}_{2}$ alone.
\end{abstract}

Correspondence to: Dr Anna Pick Kiong Ling, Department of Human Biology, International Medical University, 126 Jalan Jalil Perkasa 19, Bukit Jalil, Kuala Lumpur 57000, Malaysia

E-mail: anna_ling@imu.edu.my

Abbreviations: DCFH-DA, 2',7'-dichlorodihydrofluoresceindiacetate; MNTD, maximum non-toxic dose; 1/2MNTD, half maximum non-toxic dose; MTT, 3-(4,5-dimethylthiazol-2-yl)-2,5diphenyltetrazolium bromide; OS, oxidative stress; ROS, reactive oxygen species

Key words: apoptosis, flavonoids, orientin, oxidative stress, reactive oxygen species
The results also showed that, although orientin at the MNTD and $1 / 2$ MNTD did not reduce intracellular ROS levels, it significantly inhibited the activity of caspases $3 / 7$. Caspase 9 was significantly inactivated with orientin at the MNTD. Findings from this study suggest that the neuroprotection conferred by orientin was the result of the intracellular mediation of caspase activity.

\section{Introduction}

The elderly population experience various health issues, particularly non-communicable diseases such as heart disease, stroke, visual impairment, hearing loss and dementia. Among these, neurodegenerative diseases account for a significant percentage. Brain pathology in the form of cerebrovascular and neurodegenerative disease is known to be a leading cause of mortality worldwide, with an incidence of $2 / 1,000$ and a total mortality rate of $8 \%$ (1-3). Examples of neurodegenerative diseases include Alzheimer's disease, which is the largest cause of dementia, Parkinson's disease, Huntington's disease and amyotrophic lateral sclerosis. Currently, there has been little to no success in discovering cures and breakthroughs for neurodegenerative diseases. This, along with the ever-growing elderly population, has become a pressing global health concern.

A common characteristic of these diseases is their resemblance in symptoms and pathogenesis, leading to their consideration as a general entity with many subtypes. Another noteworthy feature is that these diseases mainly affect the elderly population. Furthermore, pathological findings indicate that neurodegenerative diseases share similarities in their mode of cell death, in which apoptosis is implicated (4). Efforts to identify the aetiological agents for these diseases have been previously undertaken. Examples of these include protein aggregation, mitochondrial dysfunction and abnormal metal metabolism. This has led to the proposal of various different pathogenic mechanisms of disease development, including oxidative stress (OS), in which reactive oxygen species (ROS) and reactive nitrative species have been considered to be the main factors (5).

This has led to a search for antioxidants in an attempt to find those that can attenuate oxidative damage and perhaps prevent neuronal cell death. One of the heavily-researched classes of antioxidants includes flavonoids, which are ubiquitous 
in natural dietary sources. Previous studies on orientin, a less-researched flavonoid, have shown many promising properties such as radioprotection (6) and cardioprotection (7). Thereforre, the potential neuroprotective properties of orientin were investigated in this study, and the identification of its mechanisms was considered.

\section{Materials and methods}

Determination of the maximum non-toxic dose (MNTD). SH-SY5Y cells $\left(1 \times 10^{3}\right)$ were seeded into each well of a flat bottom 96-well plate (Corning, Inc., Corning, NY, USA). The cells were incubated for one day to allow for attachment and acclimatisation. When $70 \%$ confluency was reached, the cells were treated with different concentrations of orientin $(0,10$, $25,50,100,200,400,800$ and $1,000 \mu \mathrm{M})$ for a period of $24 \mathrm{~h}$. Subsequently, $10 \mu \mathrm{l}$ of 3-(4,5-dimethylthiazol-2-yl)-2,5-diphenyltetrazolium bromide (MTT) stock solution was added to each well, followed by $4 \mathrm{~h}$ of incubation at $37^{\circ} \mathrm{C}$ in a dark environment to allow the formation of purple formazan dye. After $4 \mathrm{~h}$, the solution was carefully removed. The formazan that formed was dissolved by adding $100 \mu \mathrm{l}$ of DMSO and mixing gently for $10 \mathrm{~min}$. The absorbance reading of each well at $570 \mathrm{~nm}$ was then obtained using a microplate reader (Opsys MR; Dynex Technologies, Chantilly, VA, USA). To determine the MNTD, a graph of the percentage of cytotoxicity against the concentrations of orientin was constructed.

Determination of the optimal concentration of hydrogen peroxide $\left(\mathrm{H}_{2} \mathrm{O}_{2}\right)$. The cytotoxicity of $\mathrm{H}_{2} \mathrm{O}_{2}$ towards $\mathrm{SH}-\mathrm{SY} 5 \mathrm{Y}$ cells at concentrations of $0,50,100,150,200$ and $250 \mu \mathrm{M}$ was determined using the trypan blue exclusion method. In this method, equal amounts of cell suspension were suspended with trypan blue dye and $10 \mu \mathrm{l}$ was transferred into a haemocytometer (Marienfeld Superior, Lauda-Konigshofen, Germany). The number of dead cells was then counted under a microscope and their percentage was calculated. Concurrently, intracellular ROS levels were measured using a 2',7'-dichlorodihydrofluorescein-diacetate (DCFH-DA) assay. All concentrations of $\mathrm{H}_{2} \mathrm{O}_{2}$ were freshly prepared by diluting 30\% (v/v) stock solution with DMEM.

Treatment. In order to investigate the neuroprotective effects of orientin on $\mathrm{H}_{2} \mathrm{O}_{2}$-induced apoptosis in SH-SY5Y cells, cells were assigned to a total of eight treatment groups and pre-treated (Table I). Cells treated with $50 \mu \mathrm{M}$ of D- $\alpha$-tocopherol succinate acted as the positive control. After $24 \mathrm{~h}$ of pre-treatment, cells were exposed to the optimal concentration of $\mathrm{H}_{2} \mathrm{O}_{2}$ (150 $\mu \mathrm{M}$ as pre-determined in this study) for another $24 \mathrm{~h}$. Subsequently, the cells were subjected to cell cycle analysis, and the measurement of intracellular ROS level and caspase activity.

Analysis of the cell cycle. Cell cycle analysis was performed based on the principle that cells in different phases of the cell cycle have varying amounts of genetic material. The cell cycle was divided into the Sub-G, G1, S and G2/M phases.

For cell cycle analysis, the SH-SY5Y cells $\left(1 \times 10^{6}\right)$ were first seeded in separate wells in 6-well plates (Corning, Inc.). The cells were allowed to reach $70-80 \%$ confluency before the
Table I. Treatment groups used in the investigation of the neuroprotective effects of orientin on $\mathrm{H}_{2} \mathrm{O}_{2}$-induced apoptosis in SH-SY5Y cells.

\begin{tabular}{|c|c|}
\hline Group & Treatment \\
\hline 1 & Control (untreated cells) \\
\hline 2 & $\mathrm{H}_{2} \mathrm{O}_{2}$ only $(150 \mu \mathrm{M})$ \\
\hline 3 & Orientin at MNTD $(20 \mu \mathrm{M})$ \\
\hline 4 & Orientin at $1 / 2 \mathrm{MNTD}(10 \mu \mathrm{M})$ \\
\hline 5 & Vitamin E (D- $\alpha$-tocopherol succinate) $(50 \mu \mathrm{M})$ \\
\hline 6 & Orientin at MNTD $(20 \mu \mathrm{M})+150 \mu \mathrm{M} \mathrm{H}_{2} \mathrm{O}_{2}$ \\
\hline 7 & Orientin at $1 / 2 \mathrm{MNTD}(10 \mu \mathrm{M})+150 \mu \mathrm{M} \mathrm{H}_{2} \mathrm{O}_{2}$ \\
\hline 8 & $\begin{array}{l}\text { Vitamin } \mathrm{E}(\mathrm{D} \text { - } \alpha \text {-tocopherol succinate })(50 \mu \mathrm{M}) \\
+150 \mu \mathrm{M} \mathrm{H}_{2} \mathrm{O}_{2}\end{array}$ \\
\hline
\end{tabular}

$\mathrm{H}_{2} \mathrm{O}_{2}$, hydrogen peroxide; MNTD, maximum non-toxic dose; $1 / 2$ MNTD, half MNTD.

treatment groups were initiated. After $24 \mathrm{~h}$ exposure to $\mathrm{H}_{2} \mathrm{O}_{2}$, the cells from each well were trypsinised, collected and centrifuged at $327 \mathrm{x} \mathrm{g}$ for $5 \mathrm{~min}$. The supernatant was discarded and the pellet was washed with phosphate-buffered saline (PBS). The cells were then centrifuged again and fixed with $70 \%$ ethanol. The $70 \%$ ethanol was diluted from $99.8 \%$ (v/v) ethyl alcohol (Chemar ${ }^{\circledR}$ System $^{\circledR}$, Shah Alam, Malaysia) with PBS. During fixation of the cells, care was taken to resuspend the cells gently but thoroughly to avoid clumps. The cells were then left overnight and kept at $4^{\circ} \mathrm{C}$.

After overnight ethanol fixation, the tubes were centrifuged at $327 \mathrm{x} \mathrm{g}$ for $5 \mathrm{~min}$. The supernatant was discarded and the cells were rinsed twice with PBS. DNA staining reagent $(500 \mu \mathrm{l})$ was added to the cells and they were then transferred to glass tubes for flow cytometry. The programme BD CellQuest ${ }^{\mathrm{TM}}$ (BD Biosciences, Franklin Lakes, NJ, USA) was used to analyze the results of the cell cycle analysis. Results from the cell cycle analysis were analysed based on the percentages of cells in different phases of the cell cycle.

Assessment of intracellular ROS level. DCFH-DA dye was used to measure the intracellular ROS levels of the cells in each treatment group. The principle of this assay is that, when applied to intact cells, the non-ionic, non-polar DCFH-DA crosses cell membranes and is hydrolyzed enzymatically by intracellular esterase to non-fluorescent DCFH. In the presence of ROS, DCFH is oxidised to highly fluorescent dichlorofluorescein (DCF). Thus, the intracellular DCF fluorescence can be used as an index to quantify overall ROS in the cells at an excitation wavelength of $485 \mathrm{~nm}$ and an emission wavelength of $535 \mathrm{~nm}$.

Measurement of caspase activity. The induction of apoptosis via $\mathrm{H}_{2} \mathrm{O}_{2}$ has been shown to increase the activity of the caspase class of enzymes, which is involved in the various signalling pathways of apoptosis. In particular, caspase 9 is involved in the intrinsic pathway, caspase 8 is involved in the extrinsic pathway and caspase 3 is involved in the executioner pathway. 
Therefore, three groups of caspase enzymes were monitored in this study.

A total of $1 \times 10^{4}$ cells $/ \mathrm{ml}$ was seeded into each well of a sterile white flat-bottom 96-well plate (Nunc A/S, Roskilde, Denmark). Once the cells were $70-80 \%$ confluent, they were pre-treated with their respective treatment groups for $24 \mathrm{~h}$, after which they were exposed to $150 \mu \mathrm{M} \mathrm{H}_{2} \mathrm{O}_{2}$ for another $24 \mathrm{~h}$. Subsequently, the activity of caspases $3 / 7,8$ and 9 were measured using Caspase-Glo ${ }^{\circledR} 3 / 7,8$ and 9 assay kits (Promega Corporation, Madison, WI, USA), respectively. The measurement was carried out according to the manufacturer's instructions. Luminescence was then read using a luminometer (Panomics, Santa Clara, CA, USA).

Statistical analysis. All the experiments in this study were performed in triplicate and repeated once, unless otherwise stated. The data were presented as the means \pm standard deviation (SD) and subjected to Student's t-test. $\mathrm{P}<0.05$ was considered to indicate a statistically significant difference. One-way analysis of variance (ANOVA), followed by a post-hoc multiple range test (Duncan's test) at a significance level of $5 \%$, was conducted on the data obtained during the cell cycle analysis. Statistical analyses were performed using SPSS version 18.

\section{Results}

Determination of the MNTD. The MNTD of orientin was determined by constructing graphs of the percentage of cell cytotoxicity against orientin concentration. The MNTD was regarded as the highest concentration that allows $0 \%$ cytotoxicity towards SH-SY5Y cells, with cell cytotoxicity measured using an MTT assay.

The concentration of orientin against SH-SY5Y cells was tested in the range of $0-1,000 \mu \mathrm{M}$. Its cytotoxicity-concentration relationship is presented in Fig. 1. It was clearly observed that orientin was non-cytotoxic at a concentration of $\leq 20 \mu \mathrm{M}$. This showed that the MNTD of orientin was $20 \mu \mathrm{M}$ while its half MNTD ( $1 / 2 \mathrm{MNTD})$ was as low as $10 \mu \mathrm{M}$. The results also revealed that orientin stimulated the growth of SH-SY5Y cells by $\sim 2 \%$ at the $1 / 2 \mathrm{MNTD}$. By contrast, increasing the concentration of orientin from 20 to $1,000 \mu \mathrm{M}$ markedly increased the percentage of cytotoxicity to as high as $68 \%$.

Determination of the optimal concentration of $\mathrm{H}_{2} \mathrm{O}_{2}$. To determine the optimal concentration of $\mathrm{H}_{2} \mathrm{O}_{2}$, two important parameters were considered, the ability to induce significant intracellular ROS levels and cell cytotoxicity. To achieve the objectives of this study, the optimal concentration selected was required to be the least cytotoxic concentration of $\mathrm{H}_{2} \mathrm{O}_{2}$, while also being able to induce significant ROS levels in the viable SH-SY5Y cells within $24 \mathrm{~h}$ of incubation. In this study, intracellular ROS levels were gauged using a DCFH-DA assay while the cell cytotoxicity was determined using the trypan blue exclusion method.

Fig. 2 shows the intracellular ROS levels (in a total of $1 \times 10^{4}$ viable cells) after treatment with freshly prepared $\mathrm{H}_{2} \mathrm{O}_{2}$ at concentrations of $0,50,100,150,200$ and $250 \mu \mathrm{M}$. The results demonstrate an increase in intracellular ROS with an increase in the concentration of $\mathrm{H}_{2} \mathrm{O}_{2}$ from 0 to $150 \mu \mathrm{M}$.

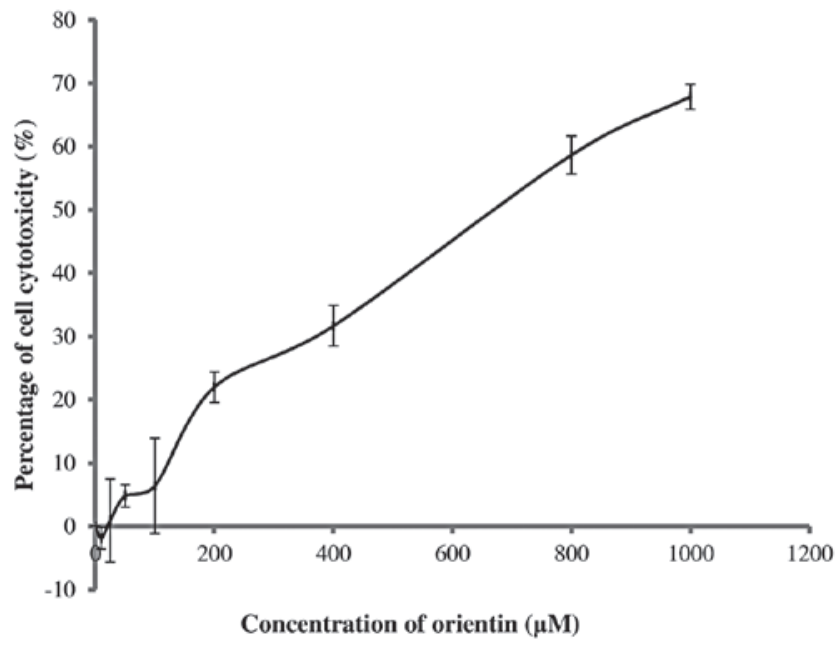

Figure 1. Percentage of cytotoxicity of SH-SY5Y cells after $48 \mathrm{~h}$ of incubation with various concentrations of orientin. Data shown are the means \pm SD of two independent experiments performed in triplicate.

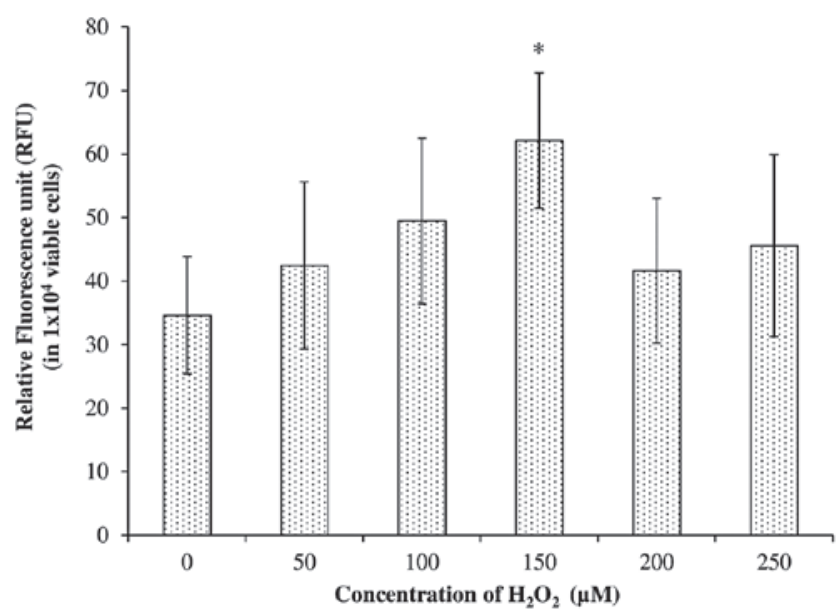

Figure 2. Intracellular reactive oxygen species levels in SH-SY5Y cells after treatment for $24 \mathrm{~h}$ with various concentrations of hydrogen peroxide $\left(\mathrm{H}_{2} \mathrm{O}_{2}\right)$. Data shown are the means \pm SD of two independent experiments performed in triplicate. ${ }^{*}$ Treatment was significantly different from the untreated cells using Student's t-test at $\mathrm{P}<0.05$.

For instance, a total increase of $23.5,42.8$ and $79.5 \%$ was achieved in cells treated with 50,100 and $150 \mu \mathrm{M}$, respectively, compared with the untreated SH-SY5Y cells. However, only the cells treated with $150 \mu \mathrm{M} \mathrm{H}_{2} \mathrm{O}_{2}$ showed a significant increase in intracellular ROS generation compared with the untreated cells, based on Student's t-test at $\mathrm{P}<0.05$. The present study also revealed that an increase in $\mathrm{H}_{2} \mathrm{O}_{2}$ concentration to 200 and $250 \mu \mathrm{M}$ failed to further increase the intracellular ROS level. Instead, it reduced the generation of intracellular ROS to $27-33 \%$ compared with a concentration of $150 \mu \mathrm{M}$.

The cytotoxicity of $\mathrm{H}_{2} \mathrm{O}_{2}$ towards $\mathrm{SH}-\mathrm{SY} 5 \mathrm{Y}$ cells was also tested at concentrations of $0,50,100,150,200$ and $250 \mu \mathrm{M}$. It was found that treatment with 50,100 and $150 \mu \mathrm{M}$ of $\mathrm{H}_{2} \mathrm{O}_{2}$ produced $<2.32 \%$ dead cells after $24 \mathrm{~h}$ of incubation, while treatment with 200 and $250 \mu \mathrm{M}$ produced a total of 5.83 and $12.28 \%$ dead cells, respectively (Fig. 3). Statistical analysis conducted using Student's t-test at $\mathrm{P}<0.05$ further revealed that treatment with 200 and $250 \mu \mathrm{M}$ significantly increased the 
Table II. Percentage of cells in the various phases of the cell cycle after treatment with orientin at the MNTD and $1 / 2$ MNTD.

Percentage of cells in each phase of the cell cycle

\begin{tabular}{lcccc}
\cline { 2 - 5 } Treatment & Sub-G & G1 & S & G2/M \\
\hline Untreated cells & $0.74 \pm 0.09$ & $64.56 \pm 7.44$ & $7.36 \pm 0.85$ & $17.11 \pm 1.97$ \\
$\mathrm{H}_{2} \mathrm{O}_{2}$ & $10.50 \pm 1.19^{\mathrm{a}}$ & $56.68 \pm 6.43$ & $8.91 \pm 1.01$ & $13.67 \pm 1.55$ \\
Orientin (MNTD) & $6.70 \pm 0.64^{\mathrm{a}, \mathrm{b}}$ & $60.15 \pm 5.74$ & $8.96 \pm 0.86$ & $15.54 \pm 1.48$ \\
Orientin (1/2MNTD) & $7.27 \pm 0.77^{\mathrm{a}}$ & $59.74 \pm 5.93$ & $8.78 \pm 0.87$ & $14.89 \pm 1.48$ \\
D- $\alpha$-tocopherol succinate $(50 \mu \mathrm{M})$ & $9.86 \pm 1.08^{\mathrm{a}}$ & $55.83 \pm 6.08$ & $8.36 \pm 0.91$ & $16.16 \pm 1.76$
\end{tabular}

Data shown are the means \pm SD of two independent experiments. One-way analysis of variance was used to analyse the Sub-G column. ${ }^{a}$ Treatment was significantly different from the untreated cells. ${ }^{b}$ Treatment was significantly different from the $\mathrm{H}_{2} \mathrm{O}_{2}$-treated cells. Other phases of the cell cycle showed no significant difference from their respective controls and the $\mathrm{H}_{2} \mathrm{O}_{2}$-exposed cells. $\mathrm{H}_{2} \mathrm{O}_{2}$, hydrogen peroxide; MNTD, maximum non-toxic dose; $1 / 2$ MNTD, half MNTD.

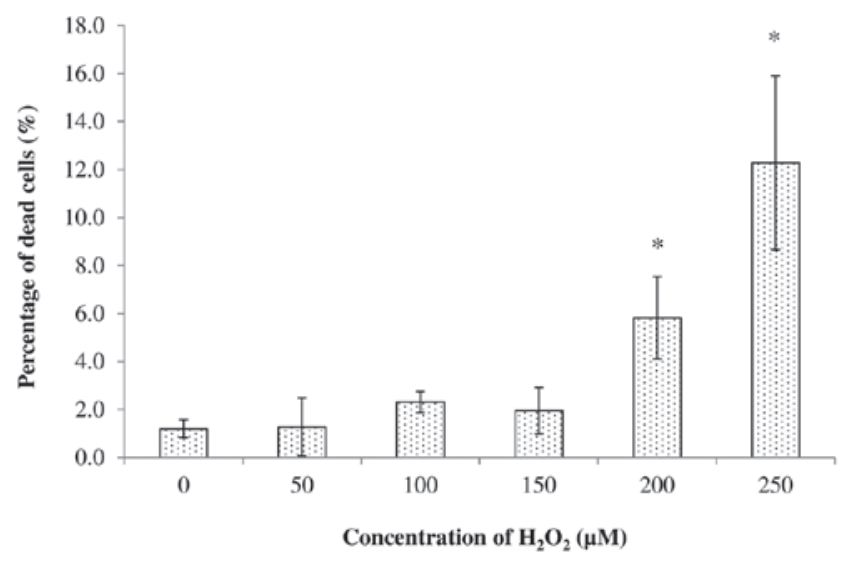

Figure 3. Percentage of dead cells as determined by the trypan blue exclusion method after treating SH-SY5Y cells for $24 \mathrm{~h}$ with various concentrations of hydrogen peroxide $\left(\mathrm{H}_{2} \mathrm{O}_{2}\right)$. Data shown are the means $\pm \mathrm{SD}$ of two independent experiments performed in triplicate. ${ }^{*}$ Treatment was significantly different from the untreated cells using Student's t-test at $\mathrm{P}<0.05$.

percentage of dead cells compared with the untreated cells. This indicated that the concentrations of 200 and $250 \mu \mathrm{M}$ were not suitable for use in subsequent experiments. By considering the ability to significantly increase the intracellular ROS levels, and the percentage of dead cells after treatment, the optimal concentration of $\mathrm{H}_{2} \mathrm{O}_{2}$ for SH-SY5Y cells after $24 \mathrm{~h}$ of incubation was found to be $150 \mu \mathrm{M}$. Thus, this optimal concentration was used in subsequent experiments.

Effects on cell cycle progression. The apoptosis of neural cells has been reported to be important in neurodegenerative diseases. Therefore, the effects of orientin on the apoptosis of SH-SY5Y cells were also determined using the propidium iodide staining method. The cell cycles of the treated cells were then analysed and compared with those of the untreated cells. Data from the cell cycle analysis were then presented as percentages of cells in each phase of the cell cycle, i.e., the sub-G, G1, S and G2/M phases (Table II). The sub-G phase represents the apoptotic cells, while the G2/M phase represents the cells that underwent mitosis.

In the untreated SH-SY5Y cells, two peaks were clearly observed at the G1 and G2/M phases (Fig. 4), which represented
64.56 and $17.11 \%$ of the cells, respectively (Table II). A total of $7.36 \%$ of the cells were in the S phase while only $0.74 \%$ of the cells were considered to be apotoptic cells in the sub-G phase. A similar number of peaks and a similar pattern of distribution were also observed in the cells treated with $50 \mu \mathrm{M}$ of $\mathrm{D}-\alpha$-tocopherol succinate, which acted as the positive control. However, this positive control showed a significantly higher percentage of apoptotic cells $(9.68 \%)$ and cells in the S phase $(8.36 \%)$ compared with the untreated cells.

By contrast, the exposure of SH-SY5Y cells to $\mathrm{H}_{2} \mathrm{O}_{2}$ was found to decrease the percentage of cells in the G1 phase $(56.68 \%)$, while increasing the percentage of cells in the sub-G phase (10.50\%), compared with the untreated cells. $\mathrm{H}_{2} \mathrm{O}_{2}$ treatment also reduced the percentage of mitotic cells (those in the G2/M phase) to as low as $13.67 \%$. This $\mathrm{G} 2 / \mathrm{M}$ phase value was the lowest among all the treatments. The results also revealed that the percentage of apoptotic cells was significantly reduced with the inclusion of orientin at either the MNTD or $1 / 2$ MNTD. Orientin at the MNTD and $1 / 2$ MNTD was able to decrease the percentage of apoptotic cells from $10.50 \%$ in the $\mathrm{H}_{2} \mathrm{O}_{2}$ treatment group to 6.70 and $7.72 \%$, respectively. Conversely, the percentage of cells in the G1 phase was increased by $\geq 5 \%$ after treatment with orientin.

Effects on intracellular ROS levels. As intracellular ROS are involved in in neurodegenerative diseases, this study also evaluated the effects of orientin at the MNTD and $1 / 2$ MNTD on intracellular ROS levels in SH-SY5Y cells. The results of the present study revealed that, by exposing the cells to $150 \mu \mathrm{M} \mathrm{H}_{2} \mathrm{O}_{2}$, intracellular ROS levels were significantly increased regardless of the treatment group, compared with the untreated cells (Fig. 5). However, cells pre-treated with orientin did not show a significant reduction in intracellular ROS levels.

Effects on caspase activity. The effectiveness of orientin as a neuroprotective agent was further evaluated by determining the mechanism of apoptosis through caspase activation. In this study, SH-SY5Y cells were pre-treated with orientin for $24 \mathrm{~h}$ prior to exposure to $150 \mu \mathrm{M}$ of freshly prepared $\mathrm{H}_{2} \mathrm{O}_{2}$ for another $24 \mathrm{~h}$. Upon completion of the treatment period, the 

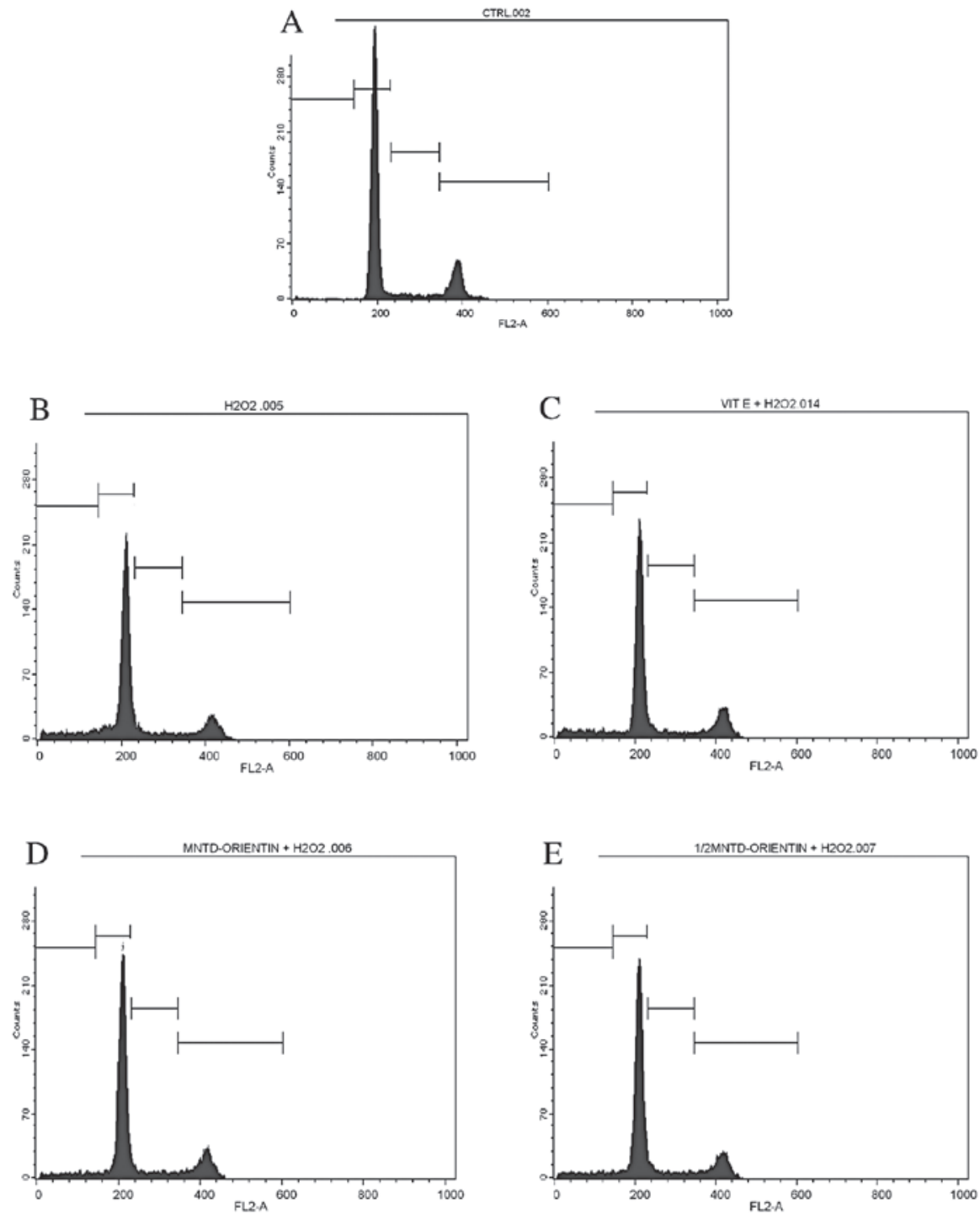

Figure 4. DNA histrograms of the cell cycle as stained by propidium iodide and analysed using flow cytometry. (A) Untreated cells. (B) Hydrogen peroxide $\left(\mathrm{H}_{2} \mathrm{O}_{2}\right)$ treatment. (C) D- $\alpha$-tocopherol succinate. (D) Orientin at the maximum non-toxic dose (MNTD). (E) Orientin at the half MNTD.

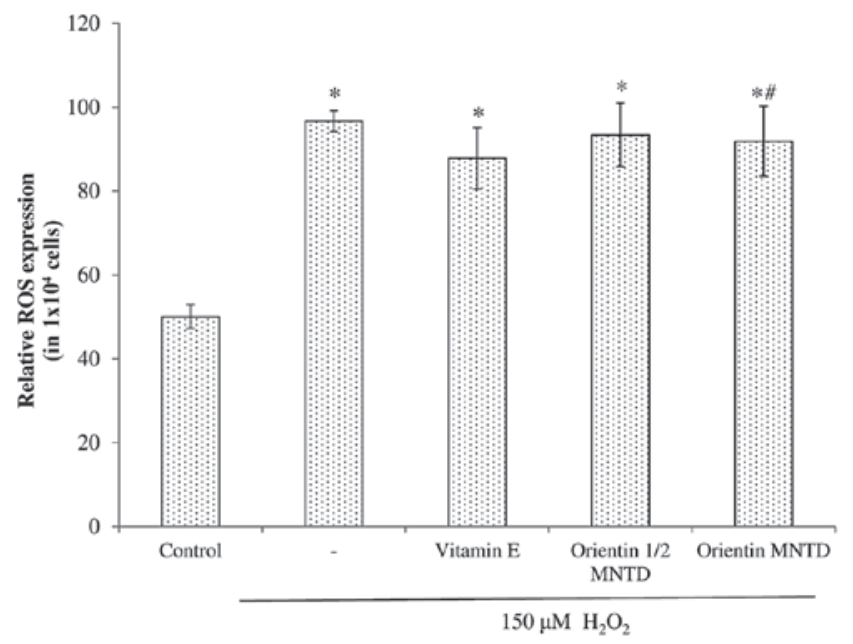

Figure 5. Effects of orientin at the maximum non-toxic dose (MNTD) and half MNTD on intracellular reactive oxygen species (ROS) levels in SH-SY5Y cells. Data shown are the means \pm SD of two independent experiments performed in triplicate. "Treatment was significantly different from the untreated cells. "Treatment was significantly different from the $\mathrm{H}_{2} \mathrm{O}_{2}$-treated cells using Student's t-test at $\mathrm{P}<0.05$. activity of caspases 3/7, 8 and 9 was measured using Promega Caspase-Glo ${ }^{\circledR}$ detection kits.

The effectiveness of orientin as a neuroprotective agent was further evaluated by determining the mechanism of apoptosis through caspase activation. Fig. 6 shows the comparison of caspase 3/7 activity in the various treatment groups, all of which show significant increases in caspase 3/7 activity when exposed to $\mathrm{H}_{2} \mathrm{O}_{2}(\mathrm{P}<0.05$ compared with the untreated cells). Out of the five treatment groups, three [positive control (D- $\alpha$-tocopherol succinate), $1 / 2$ MNTD orientin and MNTD orientin] led to a significant reduction in caspase $3 / 7$ activity compared with the $\mathrm{H}_{2} \mathrm{O}_{2}$ group, in the following ascending order: positive control, MNTD orientin and $1 / 2 \mathrm{MNTD}$ orientin.

The exposure of SH-SY5Y cells to $\mathrm{H}_{2} \mathrm{O}_{2}$ led to significant increases in caspase 8 activity when compared with the untreated cells $(\mathrm{P}<0.05)$ (Fig. 7). All the treatment groups showed a capacity to decrease caspase 8 activity, but this capacity was insignificant compared with that of the $\mathrm{H}_{2} \mathrm{O}_{2}$ treatment group. By contrast, all the treatment groups significantly increased caspase 9 activity compared with the untreated cells (Fig. 8). However, only the MNTD of orientin 


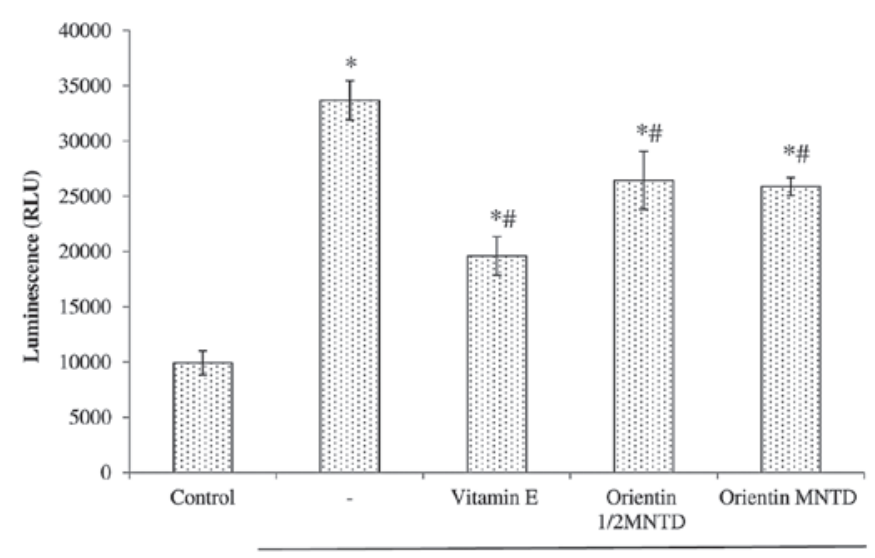

$150 \mu \mathrm{M} \mathrm{H}_{2} \mathrm{O}_{2}$

Figure 6. Effects of orientin at the maximum non-toxic dose (MNTD) and half MNTD on caspases 3/7 activity. Data shown are the means \pm SD of three replicates. "Treatment was significantly different from the untreated cells. " Treatment was significantly different from the $\mathrm{H}_{2} \mathrm{O}_{2}$-treated cells using Student's t-test at $\mathrm{P}<0.05$.

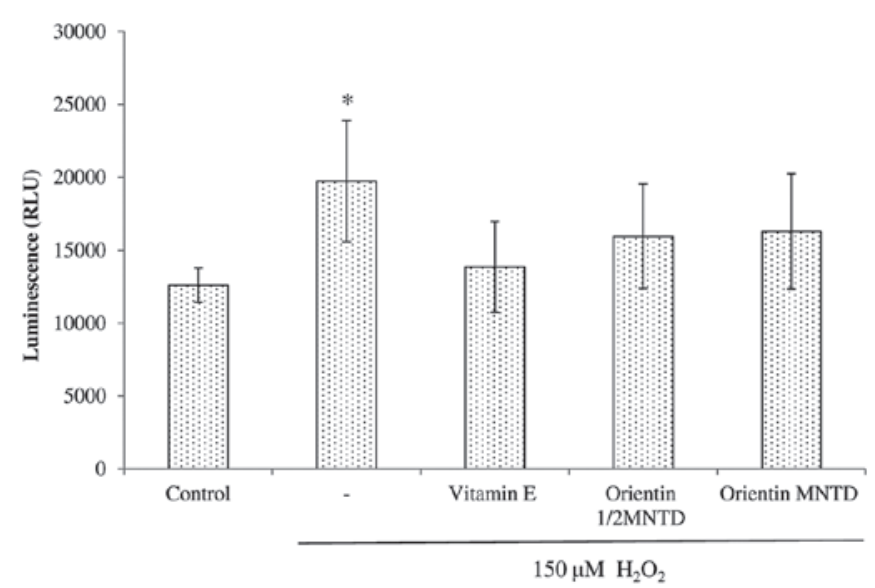

Figure 7. Effects of orientin at the maximum non-toxic dose (MNTD) and half MNTD on caspases 8 activity. Data shown are the means \pm SD of three replicates. "Treatment was significantly different from the untreated cells.

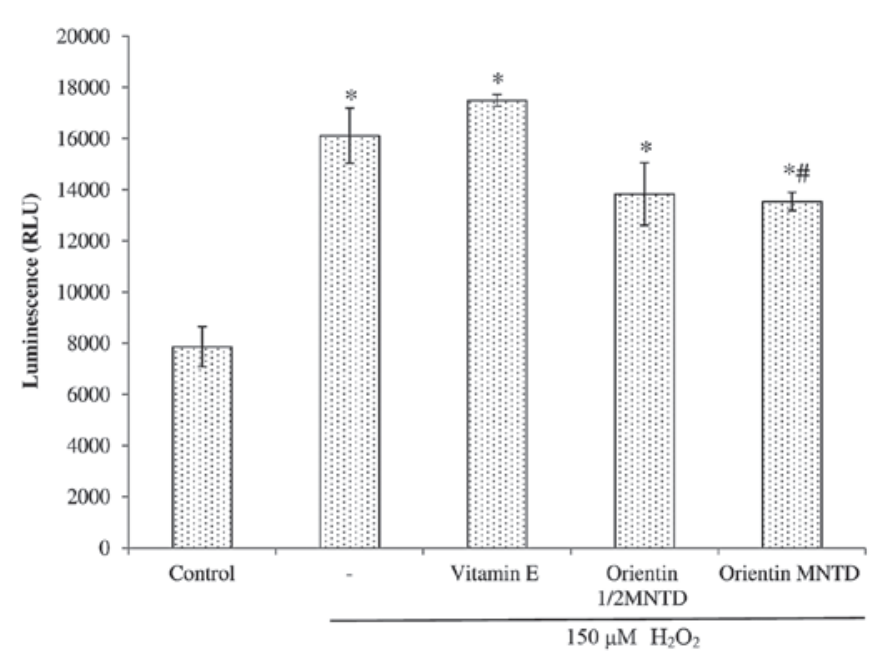

Figure 8. Effects of orientin at the maximum non-toxic dose (MNTD) and half MNTD on caspases 9 activity. Data shown are the means \pm SD of three replicates. *Treatment was significantly different from the untreated cells.

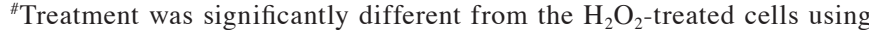
Student's t-test at $\mathrm{P}<0.5$. was able to cause a significant reduction in caspase 9 activity compared with the $\mathrm{H}_{2} \mathrm{O}_{2}$ group at $\mathrm{P}<0.05$.

\section{Discussion}

The present study revealed that orientin at concentrations below the MNTD ( $<20 \mu \mathrm{M}$ and $4.0 \mu \mathrm{g} / \mathrm{ml}$, respectively) did not exhibit any in vitro cytotoxicity towards SH-SY5Y cells, which indicated the ability of orientin to promote cell growth. This may be explained by the antioxidant properties of orientin as a flavonoid compound (8). Flavonoids are capable of protecting cells by forming bonds with free radicals that cause cell abnormalities and cell death, converting them into more stable and less reactive molecules.

Conversely, flavonoids may protect cells through interactions with various enzyme systems. An event known as lipid peroxidation, which results in cell damage, occurs when free radical species are in the presence of free iron. Flavonoid compounds may prevent this as they are known to chelate iron, thereby removing an essential factor for the development of free radicals (9). Although low concentrations of flavonoids can protect the cells from free radicals, high concentrations of flavonoids can generate ROS by auto-oxidation and redox-cycling, thereby inducing cell apoptosis as well as DNA damage (10). This may explain why the percentage of cytotoxicity increased as the concentration of orientin was increased in this study.

Based on the results of this study, a concentration of $150 \mu \mathrm{M}$ of $\mathrm{H}_{2} \mathrm{O}_{2}$ produced significant intracellular ROS levels while maintaining non-significant levels of cytotoxicity. Up to concentrations of $150 \mu \mathrm{M}$, intracellular ROS levels increased along with the concentration of $\mathrm{H}_{2} \mathrm{O}_{2}$. However, ROS levels were markedly reduced when $\mathrm{H}_{2} \mathrm{O}_{2}$ concentration was increased to $\geq 200 \mu \mathrm{M}$. This suggests that there is an optimal concentration for inducing intracellular ROS levels in the SH-SY5Y cell line. Notably, in studies on prokaryotes such as Escherichia coli, ROS has been shown to be able to activate the expression of gene products involved in antioxidant defences such as Mn-SOD (11) and catalase (12). This suggests that ROS are involved in redox homeostasis by influencing signalling pathways. This is further supported by studies that show that multicellular organisms can respond to $\mathrm{H}_{2} \mathrm{O}_{2}$ in a variety of ways, including increased antioxidant gene expression (13-15), stimulation of cell proliferation $(16,17)$, differentiation $(18,19)$, migration (20) and apoptosis $(21,22)$. However, the reason for these cells (SH-SY5Y) reducing ROS levels following exposure to $\mathrm{H}_{2} \mathrm{O}_{2}$ concentrations $\geq 200 \mu \mathrm{M}$ is unclear and merits investigation. It is possible that these cells possess the ability to upregulate the expression of antioxidative products when in contact with certain concentrations of ROS, which in this case was $\mathrm{H}_{2} \mathrm{O}_{2}$.

Findings of this study also demonstrated an apparent dose-dependent increase in cytotoxicity, possibly due to the nature of $\mathrm{H}_{2} \mathrm{O}_{2}$ and the antioxidative capacity of the cells. $\mathrm{H}_{2} \mathrm{O}_{2}$ has been shown to be highly soluble, diffusible and able to cross the cell membrane. Once across the cell membrane, the antioxidant defenses of the cells counteract $\mathrm{H}_{2} \mathrm{O}_{2}$ and the subsequently-produced ROS, but reach a threshold and eventually succumb to severe oxidative damage, leading to cell death (23). This follows the process of apoptotic cell death 
reported in fetal rat hepatocytes, where apoptosis is preceded first by ROS production, and then by the loss of mitochondrial transmembrane potential, the release of cytochrome $c$ and the activation of caspase 3 (24).

$\mathrm{H}_{2} \mathrm{O}_{2}$ has been used extensively as an inducer of OS in in vitro models $(25,26) . \mathrm{H}_{2} \mathrm{O}_{2}$ induces apoptosis in various cell lines $(25,27)$ and has been used in numerous other studies to induce OS in the SH-SY5Y cell line. The optimal concentration of $\mathrm{H}_{2} \mathrm{O}_{2}$ selected for this study $(150 \mu \mathrm{M})$ was also the concentration of $\mathrm{H}_{2} \mathrm{O}_{2}$ used by Zhang et al (28), but varies with that used in other studies. This is probably due to the different periods of exposure to $\mathrm{H}_{2} \mathrm{O}_{2}$. For example, Tarozzi et al (29) used $0.3 \mathrm{mM}$ with an exposure period of $3 \mathrm{~h}$. Even with $24 \mathrm{~h}$ exposure, a different optimal concentration of $\mathrm{H}_{2} \mathrm{O}_{2}$ has been used. Kwon et al (30) exposed cells to $400 \mu \mathrm{M}$ $\mathrm{H}_{2} \mathrm{O}_{2}$ while Suematsu et al (31) used $100 \mu \mathrm{M}$ of $\mathrm{H}_{2} \mathrm{O}_{2}$ for the same exposure period. The different periods of exposure differ according to the types of assays used in the particular studies. For example, all the cell viability tests mentioned in the above studies used a 24-h exposure period. The studies also observed different parameters, such as in the study by Tarozzi et al (29) where assays for mitochondrial functioning were performed on cells exposed to $300 \mu \mathrm{M}$ of $\mathrm{H}_{2} \mathrm{O}_{2}$ for $3 \mathrm{~h}$; for detecting ROS formation, the duration of exposure was only $30 \mathrm{~min}$, and for gauging the extent of DNA fragmentation, the cells were exposed to $300 \mu \mathrm{M}$ of $\mathrm{H}_{2} \mathrm{O}_{2}$ for $18 \mathrm{~h}$. These different tests gauge different components of the cells which show changes at varying times. For example, the mitochondria are extremely sensitive to ROS levels as their membrane potential may be markedly affected, impairing function and leading to cell death if the reading is taken later than $3 \mathrm{~h}$. By contrast, DNA fragmentation requires the activation of caspase-activated DNase, which is activated during the caspase cascade of apoptosis, specifically caspase 3 (32). Therefore, these sequences of events may require extended periods, although much of the data in this particular cell line are unclear.

The evaluation of orientin in the current study showed that it confers neuroprotection on an SH-SY5Y neuroblastoma cell line that has been induced to undergo apoptosis via exposure to $\mathrm{H}_{2} \mathrm{O}_{2}$. The treatment groups were not compared to vehicle-treated control groups, as previous results (data not included) have indicated small differences in readings. Based on the results of the cell cycle analysis, orientin led to a significant decrease in the percentages of cells in the sub-G phase, which represent the population of apoptotic cells. This finding signifies that pre-treatment with orientin may directly or indirectly reduce the incidence of apoptosis caused by exposure to $\mathrm{H}_{2} \mathrm{O}_{2}$, indicating neuroprotective properties. These are defined by any therapeutic strategy that is able to slow or arrest the progression of neuronal loss (33).

However, the mechanism of neuroprotection conferred by orientin remains unknown. The only indication to this end is that it belongs to a class of the flavonoid family $(6,34)$. Flavonoids have been known to exhibit anti-inflammatory, antiallergic, antiviral and antitumor activities, and these have been speculated to be heavily dependent on their intrinsic antioxidative and chelating properties (9), as well as on their role in the modulation of intracellular signals which promote cellular survival. For example, severe inhibition of sustained activation of c-Jun N-terminal kinase was reported in mouse striatal neurons that had been pre-treated with epicatechin and exposed to low-density lipoprotein, an apoptosis-inducing agent (35).

The results of this study indicate that orientin at the MNTD and $1 / 2$ MNTD had no significant effect on the intracellular ROS levels of viable SH-SY5Y cells that were exposed to $\mathrm{H}_{2} \mathrm{O}_{2}$, indicating that it is unable to mediate intracellular ROS levels. To confirm the protection against $\mathrm{H}_{2} \mathrm{O}_{2}$-mediated apoptosis by orientin, triggering of the caspase cascade that results in apoptosis was also investigated. The present study revealed that orientin was capable of triggering the caspase cascade. Orientin at the MNTD exhibited a reduction in the activity of caspase 3/7 and caspase 9 , which are the execution and intrinsic pathway caspases; the $1 / 2 \mathrm{MNTD}$ of orientin reduced only the activity of caspase $3 / 7$.

Several other flavonoids, such as apigenin $(36,37)$ and kaempferol (37), have also been shown to reduce the activity of caspase 3/7. Therefore, the neuroprotection conferred by orientin could most likely be expressed through this mechanism of caspase modulation, or intracellular signalling leading to decreased caspase expression, possibly through the expression of cell survival signalling. This could be due to the expression of the B-cell lymphoma 2 (Bcl-2) family of proteins, which inhibits the formation of mitochondrial transition pores. This blocks the release of cytochrome $c$, which is essential in the events leading to the caspase cascade (38). In addition, the significant reduction in caspase 9 activity in SH-SY5Y cells pre-treated with orientin indicates that orientin affects the expression of caspase 9, or is directly involved in its inactivation. This may also affect the activity of caspase $3 / 7$, as caspase 9 is involved in its activation.

In conclusion, the present study has demonstrated that orientin attenuated neuronal cell apoptosis by reducing the activity of caspases $3 / 7,8$ and 9 . As its underlying mechanism remains unknown, this could serve as a future point of investigation. For instance, caspase 3/7 activity could be due to increased Bcl-2 protein expression, which favours cell survival. Alternatively, it could be due to other factors such as the direct inhibition of the enzyme itself. Western blot analysis could be carried out to determine the expression of pro-survival proteins and cytochrome $c$. This may elucidate the promising potential of orientin as a neuroprotective agent.

\section{Acknowledgements}

This study was supported by the International Medical University under BMS I01-2012(02). The authors would like to thank Dr Say Yee How for generously providing the SH-SY5Y cells and Ms. Yee Lian Tiong for technical help with the flow cytometry work.

\section{References}

1. Kolominsky-Rabas PL, Sarti C, Heuschmann PU, Graf C, Siemonsen S, Neundoerfer B, Katalinic A, Lang E, Gassmann KG and von Stockert TR: A prospective community-based study of stroke in Germany - the Erlangen Stroke Project (ESPro): incidence and case fatality at 1, 3, and 12 months. Stroke 29: 2501-2506, 1998

2. Samsa GP, Bian J, Lipscomb J and Matchar DB: Epidemiology of recurrent cerebral infarction: a medicare claims-based comparison of first and recurrent strokes on 2-year survival and cost. Stroke 30: 338-349, 1999. 
3. Leppälä JM, Virtamo J, Fogelholm R, Albanes D and Heinonen OP: Different risk factors for different stroke subtypes: association of blood pressure, cholesterol, and antioxidants Stroke 30: 2535-2540, 1999.

4. Mattson MP: Neuronal life-and-death signaling, apoptosis, and neurodegenerative disorders. Antioxid Redox Signal 8: 1997-2006, 2006.

5. Emerit J, Edeas M and Bricaire F: Neurodegenerative diseases and oxidative stress. Biomed Pharmacother 58: 39-46, 2004.

6. Vrinda B and Uma Devi P: Radiation protection of human lymphocyte chromosomes in vitro by orientin and vicenin. Mutat Res 498: 39-46, 2001.

7. Lu N, Sun Y and Zheng X: Orientin-induced cardioprotection against reperfusion is associated with attenuation of mitochondrial permeability transition. Planta Med 77: 984-991, 2011

8. Pusztai R, Béládi I, Bakai M, Mucsi I and Kukán E: Study on the effect of flavonoids and related substances. I. The effect of quercetin on different viruses. Acta Microbiol Acad Sci Hung 13: $113-118,1966$

9. Korkina LG and Afanas'ev IB: Antioxidant and chelating properties of flavonoids. Adv Pharmacol 38: 151-163, 1997.

10. Matsuo M, Sasaki N, Saga K and Kaneko T: Cytotoxicity of flavonoids toward cultured normal human cells. Biol Pharm Bull 28: 253-259, 2005.

11. Hassan HM and Fridovich I: Regulation of the synthesis of superoxide dismutase in Escherichia coli. Induction by methyl viologen. J Biol Chem 252: 7667-7672, 1977.

12. Yoshpe-Purer Y, Henis Y and Yashpe J: Regulation of catalase level in Escherichia coli K12. Can J Microbiol 23: 84-91, 1977.

13. An JH and Blackwell TK: SKN-1 links C. elegans mesendodermal specification to a conserved oxidative stress response. Genes Dev 17: 1882-1893, 2003.

14. Inoue $\mathrm{H}$, Hisamoto $\mathrm{N}$, An JH, Oliveira RP, Nishida E, Blackwell TK and Matsumoto K: The C. elegans p38 MAPK pathway regulates nuclear localization of the transcription factor SKN-1 in oxidative stress response. Genes Dev 19: 2278-2283, 2005.

15. Sablina AA, Budanov AV, Ilyinskaya GV, Agapova LS, Kravchenko JE and Churnakov PM: The antioxidant function of the p53 tumor suppressor. Nat Med 11: 1306-1313, 2005.

16. Foreman J, Demidchik V, Bothwell JH, Mylona P, Miedema H, Torres MA, Linstead P, Costa S, Brownlee C, Jones JD, et al: Reactive oxygen species produced by NADPH oxidase regulate plant cell growth. Nature 422: 442-446, 2003.

17. Geizst $M$ and Leto TL: The Nox family of NAD(P)H oxidases: host defense and beyond. J Biol Chem 279: 51715-51718, 2004.

18. Li J, Stouffs M, Serrander L, Banfi B, Bettiol E, Charnay Y, Steger K, Krause KH and Jaconi ME: The NADPH oxidase NOX4 drives cardiac differentiation: Role in regulating cardiac transcription factors and MAP kinase activation. Mol Biol Cell 17: 3978-3988, 2006.

19. Sauer H, Rahimi G, Hescheler J and Wartenberg M: Role of reactive oxygen species and phosphatidylinositol 3-kinase in cardiomyocyte differentiation of embryonic stem cells. FEBS Lett 476: 218-223, 2000.

20. Ushio-Fukai M: Localizing NADPH oxidase-derived ROS. Sci STKE 2006: re8, 2006.

21. Cai H: Hydrogen peroxide regulation of endothelial function: origins, mechanisms, and consequences. Cardiovasc Res 68: $26-36,2005$
22. Gechev TS and Hille J: Hydrogen peroxide as a signal controlling plant programmed cell death. J Cell Biol 168: 17-20, 2005.

23. Whittemore ER, Loo DT, Watt JA and Cotman CW: A detailed analysis of hydrogen peroxide-induced cell death in primary neuronal culture. Neuroscience 67: 921-932, 1995.

24. Satoh T, Sakai N, Enokido Y, Uchiyama Y and Hatanaka H: Free radical-independent protection by nerve growth factor and Bcl-2 of PC12 cells from hydrogen peroxide-triggered apoptosis. J Biochem 120: 540-546, 1996.

25. Jacobson MD: Reactive oxygen species and programmed cell death. Trends Biochem Sci 21: 83-86, 1996

26. Uberti D, Piccioni L, Colzi A, Bravi D, Canonico PL and Memo M: Pergolide protects SH-SY5Y cells against neurodegeneration induced by $\mathrm{H}_{2} \mathrm{O}_{2}$. Eur J Pharmacol 434: 17-20, 2002.

27. Heo SR, Han AM, Kwon YK and Joung I: p62 protects SH-SY5Y neuroblastoma cells against $\mathrm{H}_{2} \mathrm{O}_{2}$-induced injury through the PDK1/Akt pathway. Neurosci Lett 450: 45-50, 2009.

28. Zhang L, Yu H, Sun Y, Lin X, Chen B, Tan C, Cao G and Wang Z: Protective effects of salidroside on hydrogen peroxide-induced apoptosis in SH-SY5Y human neuroblastoma cells. Eur J Pharmacol 564: 18-25, 2007.

29. Tarozzi A, Morroni F, Hrelia S, Angeloni C, Marchesi A, Cantelli-Forti G and Hrelia P: Neuroprotective effects of anthocyanins and their in vivo metabolites in SH-SY5Y cells. Neurosci Lett 424: 36-40, 2007.

30. Kwon SH, Kim JA, Hong SI, Jung YH, Kim HC, Lee SY and Jang CG: Loganin protects against hydrogen peroxide-induced apoptosis by inhibiting phosphorylation of JNK, p38, and ERK 1/2 MAPKs in SH-SY5Y cells. Neurochem Int 58: 533-541, 2011.

31. Suematsu N, Hosoda M and Fujimori K: Protective effects of quercetin against hydrogen peroxide-induced apoptosis in human neuronal SH-SY5Y cells. Neurosci Lett 504: 223-227, 2011.

32. Elmore S: Apoptosis: a review of programmed cell death. Toxicol Pathol 35: 495-516, 2007.

33. Shoulson I: Neuroprotective clinical strategies for Parkinson's disease. Ann Neurol 32 (Suppl): S143-S145, 1992.

34. Li D, Wang Q, Yuan ZF, Zhang L, Xu L, Cui Y and Duan K: Pharmacokinetics and tissue distribution study of orientin in rat by liquid chromatography. J Pharm Biomed Anal 47: 429-434, 2008.

35. Schroeter H, Spencer JP, Rice-Evans C and Williams RJ: Flavonoids protect neurons from oxidized low-density-lipoprotein-induced apoptosis involving c-Jun N-terminal kinase (JNK), c-Jun and caspase-3. Biochem J 358: 547-557, 2001.

36. Kang SS,Lee JY, Choi YK, Kim GS and Han BH: Neuroprotective effects of flavones on hydrogen peroxide-induced apoptosis in SH-SY5Y neuroblostoma cells. Bioorg Med Chem Lett 14: 2261-2264, 2004

37. Wang CN, Chi CW, Lin YL, Chen CF and Shiao YJ: The neuroprotective effects of phytoestrogens on amyloid beta protein-induced toxicity are mediated by abrogating the activation of caspase cascade in rat cortical neurons. J Biol Chem 276: 5287-5295, 2001.

38. Woo M, Hakem R, Soengas MS, Duncan GS, Shahinian A Kagi D, Hakem A, McCurrach M, Khoo W, Kaufman SA, et al: Essential contribution of caspase 3/CPP32 to apoptosis and its associated nuclear changes. Genes Dev 12: 806-819, 1998. 